\title{
Adolescentes com Transtorno do Espectro Autista: singularidades do desenvolvimento psicossocial
}

\author{
Adolescents with Autism Spectrum Disorder: singularities of psychosocial \\ development
}

\author{
Adolescentes con Trastorno del Espectro Autista: singularidades del \\ desarrollo psicosocial
}

\author{
Amanda Pereira Risso Saad \\ Doutoranda na Universidade Federal de Mato Grosso do Sul, Campo Grande, Mato Grosso do Sul, Brasil. \\ amanda.saad@hotmail.com \\ ORCID - http://orcid.org/0000-0001-8527-4366
}

Paulo Roberto Haidamus de Oliveira Bastos

Professor doutor na Universidade Federal de Mato Grosso do Sul, Campo Grande, Mato Grosso do Sul, Brasil. phaidamus43@gmail.com

ORCID - http://orcid.org/0000-0002-8885-1461

Geisa Alessandra Cavalcante de Souza

Doutoranda na Universidade Federal de Mato Grosso do Sul, Campo Grande, Mato Grosso do Sul, Brasil. geisaacs@hotmail.com

ORCID - http://orcid.org/0000-0002-2019-3239

Recebido em 22 de janeiro 2020

Aprovado em 18 de maio de 2020

Publicado em 27 de maio de 2020

\section{RESUMO}

O desenvolvimento psicossocial apresenta características particulares em cada etapa do ciclo de vida e está vinculado com as experiências entre indivíduo e ambiente. O presente estudo caracterizou o desenvolvimento psicossocial de adolescentes com Transtorno do Espectro Autista, considerando singularidades relacionais sobre o prisma interação, inclusão e integração social, na perspectiva de pais e/ou responsáveis. Trata-se de um recorte quantitativo, a partir da aplicação de formulário autoral, com 26 pais e/ou responsáveis de adolescentes institucionalizados em entidade específica. Os resultados apontaram prejuízos principalmente nas relações pessoais e de integração social, repercutindo de modo negativo no desenvolvimento psicossocial. Neste sentido, são necessárias estratégias para ampliar o desenvolvimento desta população, com apoio às famílias, estímulo das habilidades pessoais e contato com atividades coerentes com a etapa de vida. Todavia, a carência de instrumentalização dos serviços de saúde e de socialização em ambientes integrados fomenta a necessidade de novos saberes neste contexto para a garantia da equidade.

Palavras-chave: Sistemas de Apoio Psicossocial; Adolescente; Transtorno do Espectro Autista. 


\section{ABSTRACT}

Psychosocial development presents particular characteristics at each stage of the life cycle and it is linked to the experiences between individual and environment. The present study characterized the psychosocial development of adolescents with Autism Spectrum Disorder, considering relational singularities from the perspective of interaction, inclusion and social integration, in the view of parents and / or guardians. It is a quantitative work made by the application of an authorial form to 26 parents and/or guardians of adolescents attending a specific institution. The results pointed out losses mainly in the personal relationships and social inclusion, negatively affecting the psychosocial development. In this sense, strategies are needed to expand the development of this population, with support to the families, incentive of personal skills and contact with coherent activities with the stage of life. However, the lack of instrumentalisation of health services and socialization in integrated environments fosters the need for new knowledge in this context to guarantee equity.

Keywords: Psychosocial support system; teenager; Autism Spectrum Disorder.

\section{RESUMEN}

El desarrollo psicosocial presenta características particulares en cada etapa del ciclo de vida y está vinculado con las experiencias entre individuo y ambiente. El presente estudio ha sido caracterizado con el desarrollo psicosocial de adolescentes con Trastorno del Espectro Autista, considerando las singularidades relacionales sobre el prisma interacción, inclusión y integración social, en la perspectiva de los padres y/o los responsables. Se trata de un recorte cuantitativo a partir de la aplicación de formulario de autor con 26 padres y/o responsables de adolescentes institucionalizados en una entidad específica. Los resultados apuntaron perjuicios principalmente en las relaciones personales y de integración social, repercutiendo de modo negativo en el desarrollo psicosocial. En este sentido, son necesarias estrategias para ampliar el desarrollo de esta población, con apoyo a las familias, estímulo de las habilidades personales y contacto con actividades coherentes con la etapa de vida. Sin embargo, la carencia de instrumentalización de los servicios de salud y de socialización en entornos integrados fomenta la necesidad de nuevos saberes en este contexto para la garantía de la equidad.

Palabras clave: Sistemas de apoyo psicosocial; adolescentes; Trastorno del Espectro Autista.

\section{Introdução}

No contexto psicossocial da adolescência, é comum deparar-se com a desconstrução do universo infantil, favorecendo para a estruturação de si mesmo, rumo ao universo adulto. Nesta nova fase, o adolescente vivencia experiências com o corpo e com a sexualidade, além de transformações relacionadas com o psicológico, de uma identidade em transformação, com novas representações de si mesmo (MARTY; KERNIER, 2010).

Alguns conflitos desta etapa de vida quando associados a um transtorno mostram-se mais complexos, como no caso do Transtorno do Espectro Autista (TEA), principalmente 
http://dx.doi.org/10.5902/1984686X41858

por ser caracterizado por prejuízos sociocomunicativos, comportamentos estereotipados e repertório restrito de atividades e interesses (ASSOCIAÇÃO AMERICANA DE PSIQUIATRIA, 2014).

A existência destas dificuldades demanda maior envolvimento da família a fim de impactar no preparo da pessoa com TEA (BRASIL, 2013; COSSIO; PEREIRA; RODRIGUES, 2018). No entanto, dentre os inúmeros aspectos das famílias no convívio com um membro com TEA, observa-se a dificuldade da família e da própria pessoa com TEA em desprender-se da identidade infantil para a aquisição da identidade adolescente, repercutindo na privação de vivências inerentes a esta nova etapa de vida (KERNIER; CUPA, 2012; SPROVIERI, ASSUMPÇÃO JÚNIOR, 2001).

Neste sentido, é fundamental superar tais dificuldades a fim de proporcionar a autonomia na vida do adolescente, o que de certa forma pode ocasionar distanciamento das figuras parentais e gerar conflitos e/ou impedimentos ante o processo. Todavia, o incentivo à autonomia não deve ser subestimado pelos pais, pois configura-se um importante pilar na construção da identidade (KERNIER; CUPA, 2012).

Suportes sociais e programas de atenção aos pais e/ou responsáveis mostram-se importantes ferramentas para a superação das fragilidades familiares diante da presença de um membro com TEA (COSSIO; PEREIRA; RODRIGUES, 2018; CURSINO; CURSINO; VIEIRA, 2016; DANTAS et al., 2019; FARO et al., 2019; GOMES et al., 2015). Considerando barreiras e fatores ambientais que limitam a aquisição de repertórios sociais diversificados por parte desta população, é salutar a necessidade de apoiar pais, responsáveis e familiares no que tange à dimensão psicossocial e suas repercussões no cuidado à pessoa com TEA, pressupondo fortalecimento da rede de atenção (DANTAS et al., 2019).

Além do apoio familiar, os grupos sociais também são espaços de transição entre o universo infantil e o adulto, porém podem ser um meio pelo qual os adolescentes possam proteger-se das muitas exigências e críticas e fortalecer a autoestima através da imagem remetidas pelos outros, além de proporcionarem uma comparação e um meio para obterem informações que ultrapassam o contexto familiar (BARROS, 2002; SANTROCK, 2014).

A escolha profissional é um desafio para a pessoa com deficiência, uma vez que aspectos como a formação de identidade, o conhecimento sobre os gostos pessoais e as dificuldades em fazer escolhas estão direcionadas unicamente para a deficiência 
apresentada. $\mathrm{O}$ adolescente beneficia-se com oportunidades profissionais voltadas para as suas potencialidades, criatividade e expressão de sua identidade, favorecendo para 0 desenvolvimento de um futuro profissional (TALARICO; PEREIRA; GOYOS, 2019).

Tais transformações inerentes à fase da adolescência afetam tanto a pessoa com deficiência, quanto o ambiente em que ela está envolvida. Além destes aspectos, a experiência com o mercado de trabalho auxilia para que o adolescente desenvolva seu pensamento sobre o mundo e sobre as pessoas (SANTOS; XAVIER; NUNES, 2009).

A ampliação das relações sociais, no caso de pessoas com o TEA ou com outras deficiências, também pode ocorrer por meio de vivências em instituições de tratamento com outros jovens (SCHMIDT; BOSA, 2007). Além disso, as instituições de tratamento podem constituir uma rede de apoio à família, realizando suporte emocional para as mães ou responsáveis, considerando que estes mantêm contato diário com o adolescente e tendem a sofrer mais diante dos sintomas apresentados (MORALES; SILVA; CUVERO, 2010).

As atividades esportivas e de lazer mostram-se como importantes alternativas para a ampliação das habilidades sociais, promoção de saúde e principalmente, prevenção de incapacidades e inclusão social. Além de constituir um direito, possibilita ao adolescente maior contato com outras pessoas, favorece a autonomia e a reabilitação psicossocial (BRASIL, 2013; LIRA JUNIOR, 2018; PHEBO; ROBIM, 2012).

Pesquisas com pessoas com TEA, em sua maioria, estão direcionadas à avaliação das intervenções clínicas no âmbito individual, deixando de investigar intervenções psicossociais que explorem a inter-relação dos adolescentes com os seus pares, com os seus familiares e as possíveis repercussões no seu desenvolvimento (SCHMIDT; BOSA, 2007). Os comprometimentos inerentes ao transtorno interferem no desenvolvimento de relações sociais com estes grupos, mais especificamente com o núcleo familiar, devido ao contato diário com a pessoa com TEA (COSSIO; PEREIRA; RODRIGUES, 2018).

Neste sentido, o presente estudo buscou caracterizar 0 desenvolvimento psicossocial de adolescentes com TEA, destacando peculiaridades frente às relações familiares (família nuclear), relações pessoais (amizades e namoro), integração social (lazer e trabalho), escolar e institucional. 
http://dx.doi.org/10.5902/1984686X41858

\section{Método}

Este artigo é um recorte de dissertação de mestrado, desenvolvida no Programa de Pós-Graduação Stricto Sensu em Saúde e Desenvolvimento na Região Centro-Oeste, pela Universidade Federal de Mato Grosso do Sul. A pesquisa recebeu parecer de aprovação pelo Comitê de Ética com pesquisas envolvendo seres humanos, da Universidade Federal de Mato Grosso do Sul - UFMS no 709.626, nos termos da Resolução 466/2012 do Conselho Nacional de Saúde.

Trata-se de um recorte quantitativo que caracterizou o desenvolvimento psicossocial de adolescentes com TEA, dadas singularidades relacionais sobre o prisma interação, inclusão e integração social, sob a perspectiva de pais e/ou responsáveis. Participaram do estudo todos os pais e/ou responsáveis de adolescentes diagnosticados com TEA, atendidos pela Associação de Pais e Amigos do Autista (AMA - CG), no munícipio de Campo Grande, Mato Grosso do Sul, totalizando 26 pessoas.

Quanto aos critérios de inclusão, foram requisitos: diagnóstico médico, ter idade entre 10 e 19 anos, frequência regular (semanal) na instituição. Temporalidade de matrícula, sexo, condição socioeconômica e condições de limitação referente aos diversos níveis do espectro autista não representaram fatores de impedimento, uma vez que os formulários foram aplicados aos pais e/ou responsáveis, de modo a extrair suas percepções neste contexto.

O instrumento de coleta de dados foi elaborado pela primeira autora, composto por formulário com questões estruturadas, abordando dimensões das:

Relações Familiares (quantidade de pessoas na família, número de filhos, ordem de nascimento do adolescente com TEA, participação nas decisões familiares, independência, comunicação, iniciativa, responsabilidades e afetividade);

Relações Pessoais - amizades e namoro (ambientes frequentados além da escola e instituição, realização de atividades com outros jovens, quantidade de amigos e frequência de encontros semanais, namorou ou houve interesse em namorar e iniciação sexual);

Integração Social - lazer e trabalho (frequência em ambientes de lazer e esportivos, realização de atividade laboral, utilização de mídias digitais);

Escolar (frequência à escola ou não, rendimento escolar e participação em eventos recreativos na escola); 
http://dx.doi.org/10.5902/1984686X41858

Institucional (quais tipos de tratamento recebidos, quantidade de vezes semanais e participação em atividades recreativas na instituição).

A aplicação foi individual, após sensibilização quanto ao objetivo do estudo, a qual se deu na referida instituição orquestrada às atividades terapêticas planejadas para aquele adolescente, não necessitando de deslocamento específico para realização da entrevista. A análise estatística utilizou o programa de domínio público Epi-info 7, cujos dados foram sistematizados em tabelas e gráficos.

\section{Resultados e Discussão}

\section{Caracterização das relações familiares (família nuclear)}

Aspectos relacionados à participação do adolescente nas decisões em família, independência, capacidade de comunicação, demonstração de iniciativa, envolvimento com responsabilidades e afetividade no ambiente familiar foram investigados a fim de compreender a dinâmica familiar dos adolescentes com TEA.

Em relação à participação nas decisões familiares, teve-se como intento, conhecer se o adolescente envolveu-se quando a família decidiu sobre determinado aspecto do seu cotidiano, como, por exemplo, quando o adolescente recebeu benefício assistencial pela sua condição de deficiência, se emitiu opinião em relação ao destino de tal benefício, para satisfazer alguma necessidade pessoal. As respostas qualificadas como sim foram $77 \%$, conforme apontado na Figura 1.

Maior participação de jovens com autismo em ambientes familiares, envolvendo decisões acerca das necessidades pessoais a serem supridas, tais como, escolhas sobre vestimenta ou como e com quem gostariam de passar o tempo livre são aspectos urgentes a serem desenvolvidos em programas de suporte familiar, considerando suas repercussões positivas na qualidade de vida desta população (SUÁREZ; SÁNCHEZ; RODRIGUEZ, 2019). 
http://dx.doi.org/10.5902/1984686X41858

Figura 1 - Caracterização das relações familiares (família nuclear) dos adolescentes com TEA, em Campo Grande, MS (N=26), 2020.

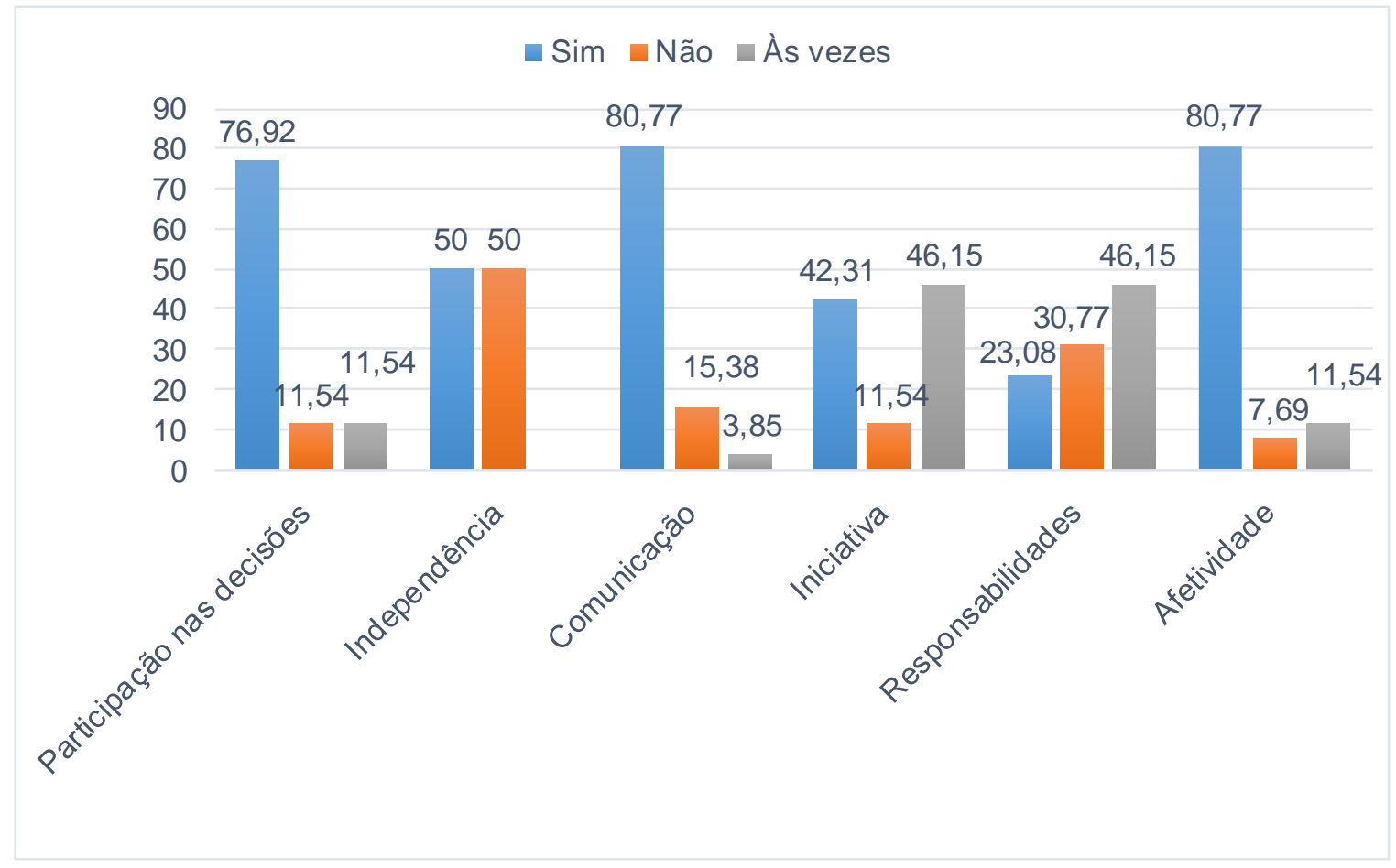

Fonte: Os autores (2020).

A fim de investigar a independência dos adolescentes com TEA, considerou-se, neste estudo, aspectos sobre o que é esperado na fase da adolescência, como a independência com o cuidado pessoal, demandas escolares, deslocamento de um local para o outro (casa - escola, entre outros) e autonomia financeira para gerir determinadas necessidades, caso o adolescente trabalhasse ou usufruísse de algum benefício.

A autonomia com cuidados pessoais teve destaque entre os aspectos relacionados à independência, totalizando $50 \%$ das respostas. Autonomia para deslocamentos e inserção no mercado de trabalho devem ser amplamente estimuladas na fase da adolescência, não devendo restringir-se apenas a cuidados pessoais, mas de uma maneira geral. A família exerce papel fundamental neste processo, a fim de favorecer conquistas e novas experiências, principalmente, para transição do universo infantil para o universo adulto (KERNIER; CUPA, 2012).

Experiências de aprendizagem ao longo da vida de pessoas com deficiência são maximizadas quando há apoio consistente às famílias, com vistas à superação das fragilidades, no sentido de que as repercussões positivas refletem no grupo familiar como um todo, mas, principalmente, no próprio desenvolvimento psicossocial da pessoa com TEA. A valorização de que a família exerce importante influência em seus membros, 
http://dx.doi.org/10.5902/1984686X41858

justamente por conhecer peculiaridades que facilitam ou atrapalham na rotina de cuidados, mostra-se como aspecto fundamental para a transição entre as diferentes fases do desenvolvimento (COSSIO; PEREIRA; RODRIGUES, 2018).

A maneira como o adolescente comunica-se com seus familiares (se de forma não verbal ou verbal), representa importante aspecto de seu desenvolvimento. Neste estudo, foram totalizadas $80,77 \%$ das respostas como não-verbal. Algumas pessoas no espectro autista tendem a não desenvolver a linguagem verbal, mas conseguem comunicar-se por meio de gestos ou expressões faciais.

O estudo de Rocha et al., (2019) demonstrou expressivos déficits de linguagem, caracterizados por nenhum ou pouco desenvolvimento da fala, acompanhados de ecolalia e foram avaliados como sinal de maior suspeita de diagnóstico de TEA em crianças. Em relação às peculiaridades da comunicação no TEA, Bosa (2007) ressalta a necessidade de um olhar cuidadoso para com esta população, pois devido à forma própria de comunicação, as necessidades e desejos podem ser incompreendidos ao utilizar sistemas de comunicação convencionais.

Profissionais e familiares devem estar atentos à utilização de comunicação suplementar e alternativa para pessoas no espectro autista, favorecendo trocas de experiências e novas possibilidades de interação social entre seus pares e outros (MORRUDO FILHO; BEZ; PASSERINO, 2013).

Para averiguar sobre aspectos envolvendo à iniciativa no desenvolvimento do adolescente, buscou-se conhecer se o mesmo apresentava iniciativa nas atividades do cotidiano, tais como cuidado pessoal, necessidades básicas ou mesmo com questões mais complexas, como para satisfazer as próprias vontades.

Segundo Kernier e Cupa (2012), a iniciativa torna possível ao adolescente maior autonomia em determinadas áreas de sua vida, sendo fundamental nesta etapa do desenvolvimento, ao mesmo tempo que exige certo distanciamento das figuras parentais. Esta autonomia mostra-se como uma situação delicada, considerando que poderá desencadear sofrimento emocional aos familiares quando não preparados para este processo. Tal complexidade pode ser observada neste estudo, uma vez que as respostas relacionadas a eventuais comportamentos com iniciativa totalizaram $46,15 \%$.

Tão importante quanto a iniciativa é o desenvolvimento de comportamentos que demonstrem responsabilidades por parte do adolescente, pois requer maturidade $e$ compreensão do ambiente ao seu redor. Neste estudo, as respostas demonstraram que 
$46,15 \%$ possuíram algum nível de responsabilidade no ambiente familiar, mas com inconstância, o que revela a importância da família em delegar algumas responsabilidades ao adolescente, de acordo com o seu nível de compreensão.

Bosa (2007) verificou, em uma pesquisa com professores que atuavam com pessoas com TEA, que existia a crença de que pessoas com TEA eram incapazes de demonstrar afeto, falar e sorrir, nomeando esta situação como uma caricatura deste espectro, ressaltada pela mídia. Observa-se no senso comum a existência da crença de que pessoas com TEA demostrem ausência ou pouca afetividade com familiares e pares de desenvolvimento. No entanto, devido à inabilidade social, alguns não conseguem demonstrar afeto da mesma maneira que as pessoas com desenvolvimento típico demonstram.

No contexto familiar, a percepção de afetividade entre os membros familiares, incluindo a pessoa com TEA, possui relação com os níveis de estresse e excesso de sobrecarga nos cuidados com a pessoa com autismo. Mães e cuidadores com diminuição de níveis de estresse tendem a perceberem seus membros mais afetuosos, em comparação com mães e cuidadores com níveis elevados de estresse (FARO et al., 2019).

A questão deste estudo, que buscou conhecer sobre a afetividade dos adolescentes com TEA, revelou que $80,77 \%$ demonstravam carinho ou mesmo correspondiam ao afeto para com os membros da família. Isso sugere que os adolescentes possuem diferentes maneiras para expressar a afetividade, tanto em ambiente escolar, quanto familiar.

\section{Caracterização das relações pessoais (amizades e namoro)}

Para caracterizar as relações pessoais, considerou-se a frequência dos jovens em ambientes diferentes dos quais são realizadas a terapia, as atividades com os pares de desenvolvimento, a quantidade de amigos ou colegas e a frequência de encontros semanais com estes, além de aspectos como namoro, desejo ou interesse em namorar e iniciação sexual.

A questão sobre a frequência em "outros" ambientes, apresentada na Tabela 1, refere-se aos ambientes diferentes da escola e instituição de tratamento e teve como intuito conhecer se o adolescente frequentou outras instituições para tratamentos complementares, totalizando $53,9 \%$ das respostas. 
http://dx.doi.org/10.5902/1984686X41858

Tabela 1 - Caracterização das relações pessoais (amizades) de adolescentes com TEA, em Campo Grande, MS (N=26), 2020.

\begin{tabular}{c|c|c}
\hline Variável & $\mathbf{N}$ & $\%$ \\
\hline Frequência em outros ambientes & & 53,90 \\
\hline Sim & 14 & 46,10 \\
\hline Não & 12 & $\mathbf{1 0 0 , 0}$ \\
\hline TOTAL & $\mathbf{2 6}$ & 3,85 \\
\hline Atividades com outros jovens & 1 & 57,69 \\
\hline Sim & 15 & 38,46 \\
\hline Não & 10 & $\mathbf{1 0 0 , 0}$ \\
\hline Às vezes & $\mathbf{2 6}$ & 80,77 \\
\hline TOTAL & 21 & 15,38 \\
\hline Quantidade de amigos/colegas & 4 & 3,85 \\
\hline Nenhum & 1 & 0 \\
\hline 1 a 2 & 0 & $\mathbf{1 0 0 , 0}$ \\
\hline 3 a 4 & $\mathbf{2 6}$ & 80,77 \\
\hline 5 ou mais & & 7,69 \\
\hline TOTAL & 21 & 11,54 \\
\hline Encontro semanal & 2 & $\mathbf{1 0 0 , 0}$ \\
\hline Sem encontros & 3 & \\
\hline 1 a 2 & $\mathbf{2 6}$ & \\
\hline 3 a 5 & & \\
\hline TOTAL & & \\
\hline & & \\
\hline
\end{tabular}

Fonte: Os autores (2020).

As atividades com outros jovens estão diretamente relacionadas com 0 desenvolvimento de habilidades inerentes ao convívio social e com a construção da identidade, conforme pontua Pino (2005). Neste sentido, observou-se que 57,69\% dos adolescentes deste estudo não realizaram tais atividades com os pares de desenvolvimento. As respostas que contaram a frequência "às vezes" $(38,46 \%)$ estiveram relacionadas com atividades na instituição de tratamento, tais como as terapias realizadas em grupo.

Um dos aspectos que se destacou refere-se à falta de amizades presentes nesta população, em uma fase em que o convívio com os grupos sociais mostra-se comum. Quanto ao número de amigos ou colegas, 80,77\% dos pais e/ou responsáveis relataram que seus filhos não possuem nenhum vínculo de amizade.

O convívio com atividades culturais, envolvendo grupos esportivos, sociais e educativos repercute de maneira ímpar na qualidade de vida de jovens com autismo. No entanto, em estudo conduzido por Suárez, Sánchez e Rodriguez (2019), observou-se que o acesso restrito desta população à vida comunitária deve ser considerado campo prioritário a ser estimulado, a fim de ampliar a qualidade de vida desses jovens.

Conforme apontam Manfezolli (2004), Papalia, Olds e Feldman (2010), a escassez das relações com os pares de desenvolvimento traz prejuízos em relação à necessidade de o adolescente pertencer a um grupo social. Mesmo quando consideradas as inabilidades 
http://dx.doi.org/10.5902/1984686X41858

sociais dos adolescentes com TEA, a falta de contato com outros jovens em ambientes não institucionais repercute de maneira negativa, prejudicando também o desenvolvimento psicossocial.

Esta característica da população estudada corrobora com estudo de Bagarollo e Panhoca (2010) sobre a subjetividade de adolescentes com TEA, os quais consideram que apesar de viverem experiências culturais importantes, possuem pouco convívio com pessoas de seu grupo etário.

A frequência de encontros semanais verificada neste estudo esteve relacionada com adolescentes que possuíam algum tipo de amizade, no entanto, mostrou-se restrita ao ambiente institucional, mais especificamente ao momento de encontro nas terapias em grupo. Segundo Sprovieri e Assumpção Júnior (2001), é comum adolescentes com TEA conviverem somente com pessoas do núcleo familiar, do ambiente de escola especial e equipe de terapeutas, gerando prejuízos ao desenvolvimento psicossocial.

O namoro na fase da adolescência representa importante pilar na construção de identidade sexual e definição de papéis sexuais, conforme ressalta Barros (2002). No entanto, os dados deste estudo totalizaram que 100\% dos adolescentes nunca namoraram, segundo seus pais e/ou responsáveis.

Além desse aspecto, observou-se que existe um estigma social nos discursos dos participantes da pesquisa em relação ao filho namorar, e de acordo com a literatura relacionada sobre sexualidade de pessoas com deficiência, pode estar vinculado ao fato da família tratar o adolescente como uma eterna criança ou como alguém que não desenvolverá o interesse em relacionar-se sexualmente com alguém (BAGAROLLO; PANHOCA, 2010; MANFEZOLLI, 2004; OTTONI; MAIA, 2019 SPROVIERI; ASSUMPÇÃO JÚNIOR, 2001).

Muito embora a sexualidade seja pouco considerada pela família, é mister destacar este aspecto como sendo um dos eixos críticos vivenciados pela pessoa com TEA. Intervenções no campo da educação sexual e reprodutiva, representam pontos de ancoragem na superação de limitações como os diversos tipos de violências no contexto de pessoas com deficiência e seus familiares e devem priorizar o ensino de habilidades de comunicação e interação social (OTTONI; MAIA, 2019). As respostas negativas em relação ao interesse em namorar totalizaram 88,55\%, e estiveram restritas ao discurso dos pais e/ou cuidadores, sugerindo em certa negação da realidade, principalmente pelo fato citado anteriormente, a respeito da infantilização dos adolescentes com deficiência. 
http://dx.doi.org/10.5902/1984686X41858

Quanto à sexualidade, 61,54\% dos adolescentes com TEA já apresentaram algum comportamento de iniciação sexual, sendo a masturbação o mais relatado.

Figura 2 - Caracterização das relações pessoais (namoro) de adolescentes com TEA, Campo Grande, MS $(\mathrm{N}=26), 2020$

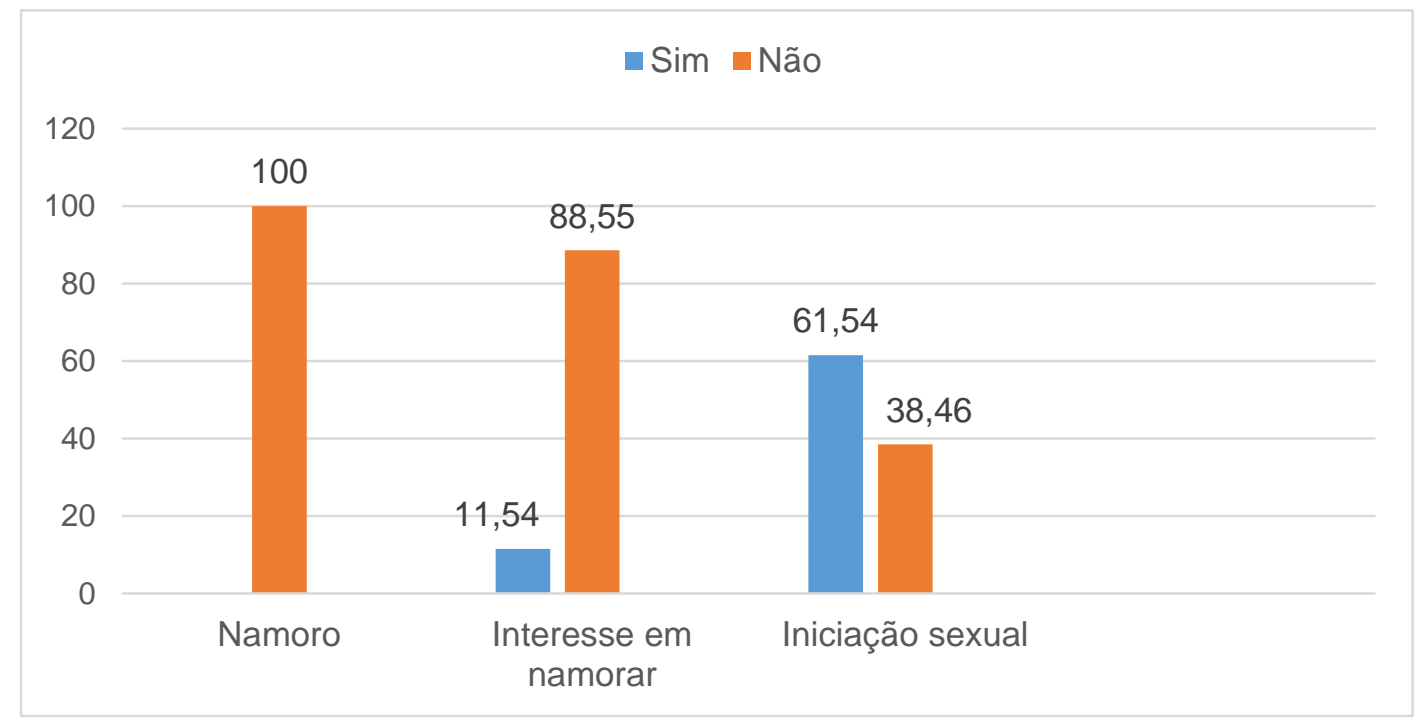

Fonte: Os autores (2020).

\section{Caracterização da integração social (lazer e trabalho)}

Para caracterização da integração social buscou-se conhecer a frequência dos adolescentes em ambientes sociais, atividades de lazer e prática de esportes, bem como aspectos relacionados ao trabalho, uso de ambientes digitais, como acesso ao computador e mídias sociais. Os ambientes sociais investigados eram referentes ao cinema, ao parque, à praça, ao shopping, à lanchonete, à igreja, além da opção "outro" local não citado pela pesquisa.

Houve destaque para a frequência às lanchonetes (84,7\%), sendo que o convívio social dos adolescentes com TEA neste ambiente ficou restrito aos pais e outros familiares. A opção referente a "outro", foi citada pela maioria dos participantes relacionada à casa de familiares, conforme apresentado na Figura 3. 
http://dx.doi.org/10.5902/1984686X41858

Figura 3 - Caracterização dos ambientes sociais frequentados por adolescentes com TEA, em Campo Grande, MS, (N=26), 2020

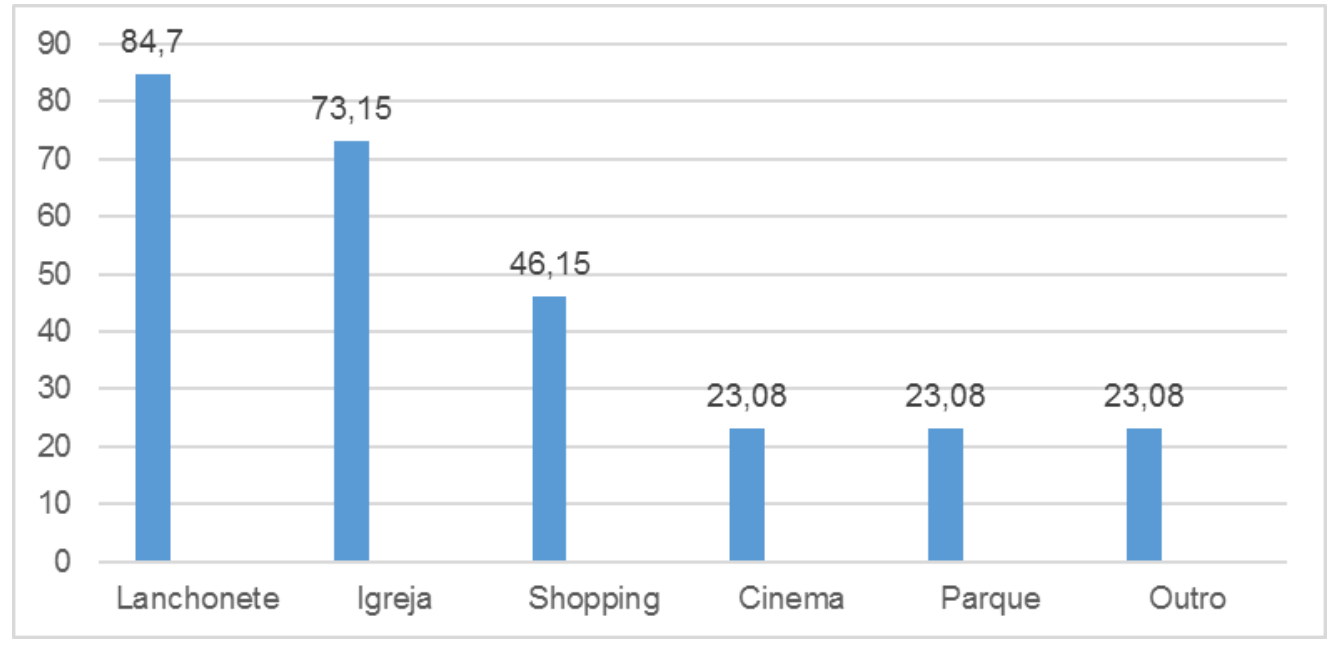

Fonte: Os autores (2020).

A limitação do convívio social ao grupo familiar merece especial atenção dos suportes sociais, considerando a relação de sobrecarga de cuidados e estresse das mães e/ou cuidador e suas influências negativas na unidade familiar e em cada um de seus membros (FARO et al., 2019).

As respostas relacionadas a prática de esportes realizada na escola e/ou instituição de tratamento, totalizaram 57,69\%, conforme a demonstrado na Figura 4. O momento de atividade física está relacionado com as atividades realizadas pelo profissional de educação física, como requisito da disciplina oferecida.

Figura 4 - Caracterização da integração social (lazer e trabalho) de adolescentes com TEA, em Campo Grande, MS, (N=26), 2020

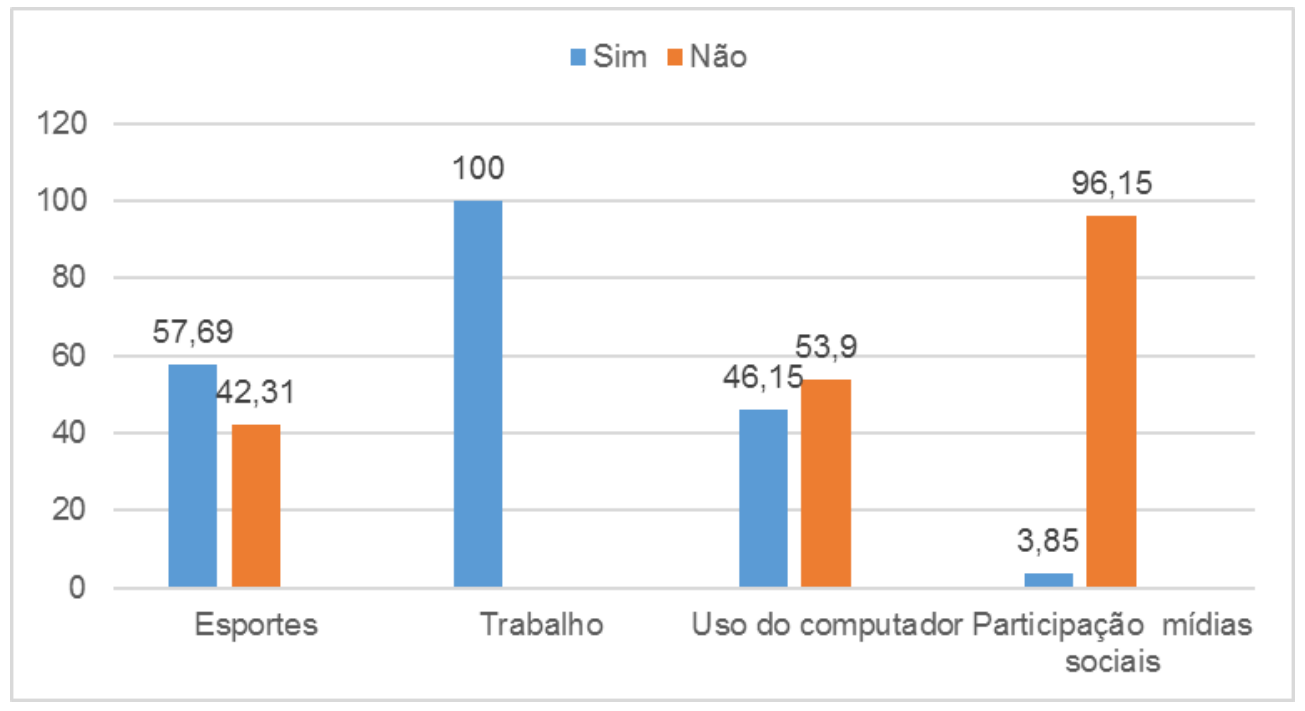

Fonte: Os autores (2020). 
http://dx.doi.org/10.5902/1984686X41858

Para melhor aproveitamento das atividades esportivas, faz-se necessário diversas adaptações que influenciam de maneira positiva para adesão ou melhor aproveitamento destas atividades por pessoas no espectro autista. Lira Júnior (2018) sugere adaptações de métodos para a inclusão social no ambiente escolar, mais especificamente, no ensino da natação.

A didática inclui o acompanhamento de profissional, monitor ou familiar junto à pessoa com transtorno, fornecendo orientações concisas, claras e objetivas acerca do que se pretende fazer, uso de gestos simples e imagens, a fim de diminuir dificuldades de concentração e ausência de contato visual. A união do Método Halliwick e do "Método ABA" (do inglês, Applied Behavior Analysis) oferece amplas possibilidades de potencializar a aprendizagem para pessoas com TEA, agregando o ensino de habilidades sociais e oportunidades de diversão, considerando a ludicidade como fator primordial de ambos os métodos (LIRA JUNIOR, 2018).

A realização destas atividades por adolescentes com TEA favorece para a melhoria ou manutenção da saúde, bem como estimula a interação social entre os praticantes, tão necessária para pessoas no espectro autista ou outras deficiências, conforme pontuam o Ministério da Saúde (2013) e Phebo e Robim (2012).

A questão, neste estudo que buscou conhecer se havia algum adolescente que trabalhasse ou mesmo estivesse passando por treinamento para a entrada no mercado de trabalho, revelou que $100 \%$ dos adolescentes não exercem uma função laboral. Alguns participantes revelaram que existe um desejo por parte de seus filhos em exercerem um trabalho, mas desacreditam nesta possibilidade, devido a inexistência de projetos que os preparem para o mercado de trabalho.

As habilidades sociais necessárias para o bom relacionamento em sociedade também podem ser treinadas em populações clínicas, como no caso de adolescentes com TEA, conforme aponta Murta (2005). Dentre as habilidades incluem a capacidade para comunicarse com o outro (iniciar, manter e finalizar uma conversa), resolução de problemas, pedidos de ajuda, aceitar ou recusar pedidos, entre outras.

Tais habilidades sociais necessárias ao exercício laboral devem ser estimuladas nos anos escolares, pensadas a partir de diferentes processos de inclusão social. Em uma revisão bibliográfica realizada para conhecer especificidades da inclusão do adulto com TEA no mercado de trabalho, observou-se que existem profundas lacunas em pesquisas científicas acerca de mecanismos eficientes que oferecem a inclusão desta população no 
http://dx.doi.org/10.5902/1984686X41858

mercado de trabalho brasileiro. Faz-se necessário articular saberes para sensibilização e promoção de conhecimentos sobre o transtorno (déficits centrais, direitos da pessoa com TEA, políticas de inclusão) para empregadores, colaboradores e familiares (TALARICO; PEREIRA; GOYOS, 2019).

Outro aspecto relevante ao adolescente com TEA refere-se ao uso do computador como facilitador da aprendizagem de uma maneira geral, sobretudo, da aproximação do adolescente com TEA com outras pessoas, segundo Passerino e Santarosa (2007).

Observou-se, neste estudo, que 53,9\% não tiveram contato com o computador e 96,15\% não acessaram as mídias sociais. Segundo o Ministério da Saúde (2013), as mídias sociais quando utilizadas com supervisão, possibilitam a ampliação das relações sociais e o fortalecimento do contato com os pares. Assim sendo, as pessoas com TEA beneficiam-se com o uso de recursos visuais, considerando a facilidade e o interesse que apresentam frente a estes estímulos.

\section{Levantamento psicossocial relacionado à escola}

Em relação ao ambiente escolar, buscou-se caracterizar a frequência, rendimento escolar e participação nos eventos recreativos neste ambiente.

Neste estudo, observou-se que 57,69\% frequentavam a escola, conforme apresentado na Tabela 2. Alguns dos adolescentes com TEA nunca frequentaram e outros frequentaram por um curto período de tempo. Identificou-se receio dos pais e/ou responsáveis em deixar o filho sob os cuidados de outras pessoas, principalmente, quando estes apresentavam problemas de comportamento ou adaptação ao ambiente escolar.

Tabela 2 - Levantamento psicossocial de adolescentes com TEA em relação à escola, em Campo Grande, MS (N=26), 2020

\begin{tabular}{|c|c|c|}
\hline Variável & $\mathbf{N}$ & $\%$ \\
\hline \multicolumn{3}{|l|}{ Frequência à escola } \\
\hline Sim & 15 & 57,69 \\
\hline Não & 11 & 42,31 \\
\hline TOTAL & 26 & 100,0 \\
\hline \multicolumn{3}{|l|}{ Rendimento escolar } \\
\hline Bom & 4 & 15,38 \\
\hline Razoável & 9 & 34,62 \\
\hline Péssimo & 2 & 7,69 \\
\hline TOTAL & 15 & 57,69 \\
\hline \multicolumn{3}{|l|}{$\begin{array}{l}\text { Frequência à eventos } \\
\text { recreativos }\end{array}$} \\
\hline Sim & 19 & 73,15 \\
\hline
\end{tabular}


Tabela 2 - Levantamento psicossocial de adolescentes com TEA em relação à escola, em Campo Grande, MS (N=26), 2020

(conclusão)

\begin{tabular}{c|c|c}
\hline Variável & $\mathbf{N}$ & $\%$ \\
\hline Não & 1 & 3,85 \\
\hline Às vezes & 6 & 23,00 \\
\hline TOTAL & $\mathbf{2 6}$ & $\mathbf{1 0 0 , 0}$ \\
\hline
\end{tabular}

Fonte: Os autores (2020).

Muito embora haja esforço do poder público em garantir o direito à educação, o acesso aos espaços educacionais especializados e/ou integrativos, compreende nó crítico no contexto da pessoa com TEA. A permanência em instituições de ensino é, ainda, limitada às condicionalidades que vão desde o acesso até a adequação singular de profissionais educadores. Nesta perspectiva, identificar elementos dificultadores da plenitude de ensino, torna-se primordial para a efetivação de direitos dedicados à esta população (LIMA; LAPLANE, 2016).

As inadequações citadas pelos pais e/ou responsáveis foram a dificuldade do adolescente em permanecer sentado durante o período de aulas e a incompreensão dos outros frente às estereotipias ou comportamentos agitados. No entanto, o contato com outras pessoas com desenvolvimento típico possibilita a aquisição de habilidades, mesmo quando inicialmente há uma esquiva em relacionar-se socialmente, conforme verificado por Bosa (2007).

Os benefícios do convívio social com pessoas com desenvolvimento típico somados aos programas de Intervenção Precoce, preferencialmente no início da infância, representam potentes ferramentas para melhoria da qualidade de vida de pessoas com TEA em diferentes contextos sociais, incluindo melhorias nas interações familiares e escolares (COSSIO; PEREIRA; RODRIGUES, 2018).

As dificuldades frequentes relatadas pela população do estudo podem ser amenizadas quando profissionais da educação articulam conhecimentos e trocam informações sobre seus estudantes com TEA, tanto com outros profissionais da educação, quanto com diferentes áreas de saberes. Em uma pesquisa que abordou a respeito da percepção de profissionais que atendiam crianças e jovens com TEA, observou-se que existia conhecimento apropriado em relação aos aspectos gerais sobre o transtorno, no entanto, havia carência de espaços formais para realização de trocas de conhecimento e construção de novos saberes (ROCHA et al., 2018). 
Ainda que as perspectivas relacionadas ao desenvolvimento da pessoa com TEA tenham enfáticas influências biomédicas, abordagens holísticas que envolvam a inclusão de outras áreas neste contexto, representam possibilidade de equilíbrio no que concerne à educação e suas repercussões na qualidade de vida dessa população. Assim, realizar estudos que atendam essa lacuna, mostra-se legítima, considerando aspectos como a formação de professores e a dialogicidade com a família e demais eixos sociais (RIOS; CAMARGO JÚNIOR, 2019; WUO, 2019; WUO; YAEDU; WAYSZCEYK, 2019).

Geralmente, o adolescente com TEA é supervisionado por professor auxiliar, responsável pela adaptação do conteúdo pedagógico e integração ao convívio com outros estudantes, quando necessário. Na questão sobre o rendimento escolar, houve destaque para as respostas "razoável" $(34,62 \%)$, seguido de "bom" e "péssimo", segundo a qualificação dos pais.

O uso de tecnologias assistivas contribui de maneira importante no processo de ensino e aprendizagem de alunos com necessidades educacionais especiais, utilizados em salas regulares e de recursos multifuncionais, diversificando o fazer profissional do educador na busca pela inclusão escolar (CÂNDIDO, SOUZA 2018).

Quando citada a participação às festividades no ambiente escolar, obteve-se $34,62 \%$ de respostas que frequentavam eventualmente. Alguns pais fizeram questão de que seus filhos participassem, mas houve pouco envolvimento com tais atividades ou com os seus pares.

A ampliação de habilidades cognitivas e sociais deve ser evidenciada não apenas em relação à sala de aula, mas também em atividades extracurriculares. Conforme ressaltam Tezzari e Baptista (2007), deve-se priorizar o agrupamento de alunos de acordo com a faixa etária, viabilizando a criação de objetivos pedagógicos de acordo com as necessidades específicas de cada estudante.

\section{Levantamento psicossocial relacionado à instituição}

Neste estudo, o levantamento psicossocial relacionado à instituição levou em consideração os atendimentos recebidos pelos adolescentes com TEA, a quantidade de atendimentos semanais e a frequência aos eventos recreativos oferecidos pela instituição de tratamento.

Observou-se que os atendimentos recebidos pela instituição seguiam uma avaliação de cada adolescente, de acordo com as potencialidades e dificuldades de cada caso. 
Neste sentido, nem sempre os adolescentes receberam todos os tratamentos oferecidos. Houve destaque para atendimentos em psicopedagogia (88,55\%), dos quais realizavam atividades por meio de oficinas em grupo, enfatizando aspectos do desenvolvimento cognitivo e habilidades de convivência social.

Em relação aos eventos recreativos oferecidos pela instituição, observou-se que $73,15 \%$ dos pais e/ou responsáveis levavam os adolescentes aos eventos, buscando a integração social entre os adolescentes e entre os próprios familiares.

Tabela 3 - Levantamento psicossocial de adolescentes com TEA em relação à instituição, em Campo Grande, MS (N=26), 2020

\begin{tabular}{c|c|c}
\hline Variável & N & $\%$ \\
\hline Atendimentos recebidos & & 88,55 \\
\hline Psicopedagogia & 23 & 77,00 \\
\hline Fonoaudiologia & 20 & 61,54 \\
\hline Psiquiatria & 16 & 61,54 \\
\hline Educação física & 16 & 57,69 \\
\hline Psicologia & 15 & 57,69 \\
\hline Terapia ocupacional & 15 & 38,46 \\
\hline Outro & 10 & $\mathbf{1 0 0 , 0}$ \\
\hline TOTAL & $\mathbf{2 6}$ & 30,77 \\
\hline Quantidade (por semana) & & 34,62 \\
\hline 1 & 8 & 26,92 \\
\hline 2 & 9 & 7,69 \\
\hline 3 & 7 & $\mathbf{1 0 0 , 0}$ \\
\hline 4 (ou mais) & 2 & \\
\hline TOTAL & $\mathbf{2 6}$ & 73,15 \\
\hline Frequência à eventos & & 3,85 \\
recreativos & 19 & 23,00 \\
\hline Sim & 1 & $\mathbf{1 0 0 , 0}$ \\
\hline Não & 6 & \\
\hline Às vezes & $\mathbf{2 6}$ & \\
\hline TOTAL & & \\
\hline
\end{tabular}

Fonte: Os autores (2020).

Mesmo as festividades em comemoração ao "dia das crianças" foram frequentadas pelos adolescentes, o que sugere, novamente, estar relacionado com o fato dos pais os verem como eternas crianças (BAGAROLLO; PANHOCA, 2010; MANFEZOLLI, 2004; SPROVIERI; ASSUMPÇÃO JÚNIOR 2001).

Esta constatação evidencia que a forma de tratamento em relação ao adolescente com TEA necessita ser alterada por pais e/ou responsáveis, profissionais de saúde, educação e comunidade em geral, no sentido de serem trabalhados aspectos que alinhem o ciclo de vida da adolescência com atividades coerentes com esta faixa etária. Neste sentido, faz-se necessários suportes sociais que atendam esta demanda e priorizem a aquisição e 
ampliação do conhecimento acerca do TEA a fim de ofertar serviços de qualidade que promovam a integração social (BRASIL, 2013).

Considerar aspectos socioeconômicos pode favorecer a elaboração de estratégias interventivas mais alinhadas às necessidades das famílias potencialmente vulneráveis, bem como fomentar o desenvolvimento de abordagens que ampliem efetivamente 0 alcance dos programas de apoio psicossocial (SPINAZOLA et al., 2018).

Como exemplo de suporte social exitoso para familiares e profissionais envolvidos com TEA, tem-se a pesquisa de Souza et al., (2019) que ofertou oficinas educativas sobre principais aspectos do TEA para pais e cuidadores, profissionais de saúde e educação, das quais verificou-se aumento do conhecimento sobre identificação precoce do transtorno, conhecimento específico para cada público-alvo e aspectos relacionados ao tratamento. Ainda que os suportes sociais sejam salutares, é relevante considerar aspectos socioeconômicos para favorecer a elaboração de estratégias interventivas mais alinhadas, conforme apontam Spinazola et al., 2018.

A ampliação do repertório de informações para diferentes populações possibilita melhorias substanciais para pessoas com TEA, no sentido de recebimento de atendimentos psicossociais de qualidade às suas especificidades (BRASIL 2013).

\section{Considerações finais}

As características presentes nas relações familiares que envolvem a participação do adolescente com TEA nas decisões familiares, independência, comunicação, iniciativa, responsabilidades e afetividade a partir da compreensão dos pais e/ou responsáveis encontram-se presentes, mas com alterações que demandam maior adaptação de todos os envolvidos com o adolescente.

As relações pessoais (amizades e namoro) dos adolescentes com TEA mostram-se prejudicadas, quando comparadas às atividades de adolescentes sem o transtorno. A pouca frequência em ambientes sociais, a falta de amigos e a não realização de atividades coerentes com a adolescência, trazem privações e repercutem de maneira negativa no desenvolvimento psicossocial desse grupo.

O mesmo foi observado quanto à integração social (lazer e trabalho), a qual apresentase restrita a determinados ambientes de convívio familiar, sem a participação de outros jovens. O estímulo das habilidades, tanto para as relações sociais, quanto para o trabalho é possível mediante projetos que visem a preparação desta população, de modo a ampliar seu 
repertório cognitivo, afetivo e comportamental, levando em consideração as dificuldades e potencialidades pessoais, a partir de uma visão holística da pessoa com deficiência.

Em relação ao ambiente escolar, o estudo aponta que os adolescentes demonstram dificuldades de inserção nesse contexto, considerando que muitos não frequentam, ou mesmo, nunca frequentaram a escola, apresentam rendimento escolar abaixo do esperado, e eventualmente, participam de atividades recreativas, o que, de fato, demonstra a necessidade de adaptação e acolhimento às demandas das pessoas com TEA.

Embora os atendimentos recebidos pela instituição de tratamento visem as atividades em grupo, observa-se que o convívio dos adolescentes se restringe aos encontros com os jovens que frequentaram a mesma terapia e às atividades recreativas da instituição, independente da temática a ser comemorada, o que inclui a comemoração do "dia das crianças", mesmo que estes já tenham passado desta fase de desenvolvimento. Dentre as principais estratégias para melhorar o desenvolvimento psicossocial de adolescentes com TEA está o auxílio às famílias. Elas devem receber apoio do poder público e de instituições especializadas, a fim de prepará-las para melhor gestão dos conflitos, estímulo da independência e convívio social de seus filhos.

Há também a necessidade de pesquisas em relação aos adolescentes e adultos com TEA, de modo a compreender as possibilidades de ampliação das habilidades pessoais, oportunizar o contato com atividades coerentes com a fase de desenvolvimento, incluindo a inserção no mercado de trabalho, atividades de lazer e esportivas. De fato, tais estratégias podem ampliar as oportunidades de convívio destes adolescentes e favorecer experiências psicossociais coerentes com esta fase da vida, minimizando a exclusão social e promovendo a ruptura de rótulos acerca da deficiência. No âmbito das intervenções, busca-se a construção de um trabalho integrado para a sensibilização das famílias e sociedade, a partir de investimentos sociais e políticos na formação de profissionais comprometidos com a melhoria da qualidade de vida e com a criação de ambientes acolhedores que priorizem a igualdade de direitos dedicados a essa população.

\section{Referências}

ASSOCIAÇÃO AMERICANA DE PSIQUIATRIA (APA). Manual Diagnóstico e Estatístico de Transtornos Mentais: DSM-5. 5 ed. Porto Alegre: Artmed, 2014.

BAGAROLLO, M. F.; PANHOCA, I. A constituição da subjetividade de adolescentes autistas: um olhar para as histórias de vida. Revista Brasileira de Educação Especial, v.16, n. 2, 2010. Disponível em: 
http://www.scielo.br/scielo.php?script=sci_arttext\&pid=S141365382010000200006\&lng=en\&nrm=iso. Acesso em: 15 abr. 2019.

BARROS, M. N. S. O psicólogo e a ação com o adolescente. In: CONTINI, M. L. J. (coord.); KOLLER, S. H. (org.). Adolescência e psicologia: concepções e reflexões críticas. Brasília: Conselho Federal de Psicologia, 2002. p. $33-45$.

BOSA, C. Autismo: atuais interpretações para antigas observações. In: BAPTISTA, C. R.; BOSA, C. (col.) Autismo e educação: reflexões e propostas de intervenção. Porto Alegre: Artmed, 2007. p. $21-39$.

BRASIL. Ministério da Saúde. Secretaria de Atenção à Saúde. Departamento de Ações Programáticas Estratégicas. Linha de cuidado para a atenção às pessoas com transtornos do espectro do autismo e suas famílias na rede de atenção psicossocial do SUS. Brasília: Ministério da Saúde, 2013. 157p.

CÂNDIDO, F. R.; SOUZA, A. M. Tecnologias assistivas e inclusão escolar: o uso do software GRID 2 no atendimento educacional especializado a estudante com autismo em uma escola pública do Distrito Federal. Revista Diálogo Educacional, v. 18, n. 58, 2018. Disponível em: https://periodicos.pucpr.br/index.php/dialogoeducacional/article/view/23953. Acesso em: 13 mai. 2020.

COSSIO, A. P; PEREIRA, A. P. S.; RODRIGUEZ, R. C. Benefícios da intervenção precoce para a família de crianças com Transtorno do Espectro do Autismo. Revista Educação Especial, v. 31, n. 60, p. 9 - 20, 2018. Disponível em:

https://periodicos.ufsm.br/educacaoespecial/article/view/28331. Acesso em: 12 mai. 2020.

CURSINO, I. G.; CURSINO, R. S. T. F; VIEIRA, S. C. M. Qualidade de vida de cuidadores de adolescentes com Transtorno do Espectro Autista: uma revisão da literatura.

Adolescência e Saúde, v.13, n. 2, p. 67 - 78, 2016.

DANTAS, K.O.; NEVES, R. F.; RIBEIRO, K. S. Q. S.; BRITO, G. E. G.; BATISTA, M. C. Repercussões do nascimento e do cuidado de crianças com deficiência múltipla na família: uma metassíntese qualitativa. Cadernos de Saúde Pública, v. 35, n. 6, p. 1-19, 2019. Disponível em: https://www.scielo.br/scielo.php?pid=S0102-

311X2019000702001\&script=sci_arttext. Acesso em: 13 mai. 2020.

FARO, K. C. A.; SANTOS, R. B.; BOSA, C. A.; WAGNER, A.; SILVA, S. S. C. Autismo e mães com e sem estresse: análise da sobrecarga materna e do suporte familiar. Psico, v. 50, n. 2, 2019. Disponível em:

http://revistaseletronicas.pucrs.br/ojs/index.php/revistapsico/article/view/30080/pdf Acesso em: 13 mai. 2020.

GOMES, T. M.; LIMA, L. H. L.; BUENO, M. K. G.; ARAÚJO, L. A.; SOUZA, M. N. Autismo no Brasil, desafios familiares e estratégias de superação: revisão sistemática. Jornal de pediatria, v. 91, n. 2, 2015. Disponível em: https://www.scielo.br/scielo.php?pid=S002175572015000200111\&script=sci_arttext\&tIng=pt. Acesso em: 18 abr. 2019. 
KERNIER, N.; CUPA, D. Adolescência: muda psíquica à procura de continentes. Ágora, v. 15, número especial, dez. 2012. Disponível em:

http://www.scielo.br/scielo.php?script=sci_arttext\&pid=S1516-

14982012000300007\&lng=en\&nrm=iso. Acesso em: 15 abr. 2019.

LIMA, S. M.; LAPLANE, A. L. F. Escolarização de alunos com autismo. Revista Brasileira de Educação Especial, v. 22, n. 2, p. 269-284, 2016. Disponível em:

https://www.scielo.br/pdf/rbee/v22n2/1413-6538-rbee-22-02-0269.pdf. Acesso em: 13 mai. 2020.

LIRA JÚNIOR, F. Considerações preliminares sobre o ensino da natação para autistas. Revista Educação Especial, p. 167-180, 2018. Disponível em: https://periodicos.ufsm.br/educacaoespecial/article/view/23474. Acesso em: 21 jan. 2020.

MANFEZOLLI, R. R. Olha eu já cresci: a infantilização de jovens e adultos com deficiência mental, 2004. Dissertação (Mestrado em Educação) - Faculdade de Educação, Universidade Metodista de Piracicaba, Piracicaba, 2004.

MARTY, F.; DE KERNIER, N. La adolescencia como paradigma de limites. Actualidad psicológica. Buenos Aires, v. 35, n. 392, 2010. p.12 - 15.

MORALES, N. M. O.; SILVA, C. H. M.; CUVERO, M.M. Qualidade de vida de cuidadores de portadores de autismo. In: ASSUMPÇÃO JÚNIOR, F. B.; KUCZYNSKI, E. (org.). Qualidade de vida na infância e na adolescência: orientações para pediatras e profissionais de saúde mental. Porto Alegre: Artmed, 2010. p. 292 - 300.

MORRUDO FILHO, C. A. R.; BEZ, M. R.; PASSERINO, L. M. Reflexões acerca do uso da comunicação alternativa em crianças com autismo na fase triádica da comunicação. In: CONGRESSO BRASILEIRO DE COMUNICAÇÃO ALTERNATIVA, 5., 2013, Gramado. Anais do V Congresso Brasileiro de Comunicação Alternativa, 2013. p. 1-08.

MURTA, G. S. Aplicações do treinamento em habilidades sociais: análise da produção nacional. Psicologia: Reflexão e Crítica, v.18, n. 2, 2005. Disponível em: https://www.redalyc.org/articulo.oa?id=188/18818217. Acesso em: 11 abr. 2019.

OTTONI, A. C. V.; MAIA, A. C. B. Considerações sobre a sexualidade e educação sexual de pessoas com transtorno do espectro autista. Revista Ibero-Americana de Estudos em Educação, v. 14, n. esp. 2, p. 1265 - 1283, 2019.

PAPALIA, D.E.; OLDS, S; FELDMAN, R. D. 0 mundo da criança: da infância à adolescência. 11 ed. Porto Alegre: Artmed, 2010.

PASSERINO, L. M.; SANTAROSA, L. C. Interação social no autismo em ambientes digitais de aprendizagem. Psicologia: reflexão e crítica, v. 20, n. 1, 2007. Disponível em: http://www.scielo.br/scielo.php?script=sci_arttext\&pid=S0102-

79722007000100008\&lng=en\&nrm=iso. Acesso em: 11 abr. 2019. 
PHEBO, L. B.; ROBIM, M. Esporte: um direito para o desenvolvimento humano. In: NOGUEIRA, K. T. (coor.); FERREIRA, E. L; VASCONCELOS, M. M. (org). Adolescência: série pediatria. Rio de Janeiro: Guanabara Koogan, 2012. p. 500 -511.

PINO, A. As marcas do humano: as origens da constituição cultural da criança na perspectiva de Lev A. Vigotski. São Paulo: Cortez, 2005.

RIOS, C.; CAMARGO JÚNIOR, K.R. Especialismo, especificidade e identidade: as controvérsias em torno do autismo no Sus. Ciência e Saúde Coletiva, v. 24, n. 3, p. 1111 120, 2019. Disponível em: https://www.scielo.br/scielo.php?script=s. Acesso em: 16 mai. 2020.

ROCHA, A. N. D. C.; COPOBIANCO, N. A. N.; BRITO, L. B.; SANTOS, A. R. dos. Intervenção junto a indivíduos com transtorno do espectro do autismo: a percepção do profissional. Revista Educação Especial, p. 417-430, 2018. Disponível em:

https://periodicos.ufsm.br/educacaoespecial/article/view/23893. Acesso em: 21 jan. 2020.

ROCHA, C. C.; SOUZA, S. M.; COSTA, A. F.; PORTES, J. R. M. O perfil da população infantil com suspeita de diagnóstico de transtorno do espectro autista atendida por um Centro Especializado em Reabilitação de uma cidade do Sul do Brasil. Physis: Revista de Saúde Coletiva. Rio de Janeiro, v. 29, n. 4, p. 1 - 20, 2019. Disponível em: https://www.scielo.br/pdf/physis/v29n4/0103-7331-physis-29-04-e290412.pd. Acesso em: 13 mai. 2020.

SANTOS, M. S.; XAVIER, A. S.; NUNES, A. I. B. L. Adolescência: aspectos históricos e biopsicossociais. In: Psicologia do Desenvolvimento: teorias e temas contemporâneos. Brasília: Liber Livro, 2009. p. 109 - 124.

SANTROCK, J. W. Adolescência. 14 ed. Porto Alegre: AMGH, 2014.

SCHMIDT, C.; BOSA, C. A. Estresse e auto-eficácia em mães de pessoas com autismo. Arquivos Brasileiros de Psicologia, v. 59, n. 2, p.179 - 191, 2007. Disponível em: http://pepsic.bvsalud.org/scielo.php?script=sci_arttext\&pid=S180952672007000200008\&lng=pt\&nrm=iso. Acesso em: 11 abr. 2019.

SUÁREZ, M. L. M.; SÁNCHEZ, L. E. G.; RODRIGUEZ, M. A. A. Inclusión social y autodeterminación: los retos en la calidad de vida de los jóvenes con autismo y discapacidad intelectual. Siglo Cero, v. 50 (3), n. 271, p. 29 - 46, 2019. Disponível em: https://revistas.usal.es/index.php/0210-1696/article/view/21374. Acesso em: 15 mai. 2020.

SOUZA, L. M. R.; GOMES, M. L. C.; SILVA, J. A.; CARVALHO, L. H. Z. S.; MARTONE, M. C. C.; CARMO, J. S. Oficinas sobre transtorno do espectro autista para pais, cuidadores e profissionais: análise de uma experiência. Revista Educação Especial, p. 1 - 19, 2019. Disponível em: https://periodicos.ufsm.br/educacaoespecial/article/view/26386. Acesso em: 21 jan. 2020. 
SPINAZOLA, C. C.; AZEVEDO, T. L.; GUALDA, D. S.; CIA, F. Correlação entre nível socioeconômico, necessidade, suporte social e recursos familiares de mães de crianças com deficiência física, síndrome de Down e autismo. Revista Educação Especial, v. 31, n. 62, p. 697 - 712, 2018. Disponível em:

https://periodicos.ufsm.br/educacaoespecial/article/view/29042. Acesso em: 12 mai. 2020.

SPROVIERI, M. H. S. Família e deficiência. In: ASSUMPÇÃO JÚNIOR, F. B; TARDIVO, L. S. L. P. C. (coord.). Psicologia do excepcional: deficiência física, mental e sensorial. Rio de Janeiro: Guanabara Koogan, 2008.

SPROVIERI, M.H.S.; ASSUMPÇÃO JÚNIOR, F.B. Dinâmica familiar de crianças autistas. Arquivos de Neuropsiquiatria, v. 59, n. 2, 2001. Disponível em: http://www.scielo.br/scielo.php?script=sci_arttext\&pid=S0004282X2001000200016\&lng=en\&nrm=iso. Acesso em: 11 abr. 2019.

TALARICO, M. V. T. S; PEREIRA, A. C. dos S.; GOYOS, A. C. de N. A inclusão no mercado de trabalho de adultos com Transtorno do Espectro do Autismo: uma revisão bibliográfica. Revista Educação Especial, p. 1 - 19, 2019. Disponível em: https://periodicos.ufsm.br/educacaoespecial/article/view/39795. Acesso em: 21 jan. 2020.

TEZZARI, M. L.; BAPTISTA, C. R. Vamos brincar de Giovani? A integração escolar e o desafio da psicose. In: BAPTISTA, C. R.; BOSA, C. (col.) Autismo e educação: reflexões e propostas de intervenção. Porto Alegre: Artmed, 2007. p. 139 - 150

WUO, A. S. Educação de pessoas com transtorno do espectro do autismo: estado do conhecimento em teses e dissertações nas regiões Sul e Sudeste do Brasil (2008 - 2016).

Saúde e Sociedade, v. 28, n. 3, p. 210 - 223, 2019. Disponível em: https://www.scielosp.org/article/sausoc/2019.v28n3/210-223/. Acesso em: 15 mai. 2020.

WUO, A. S.; YAEDU, F. B.; WAYSZCEYK, S. Déficit ou diferença? Um estudo sobre o autismo em pesquisas educacionais. Revista Educação Especial, v. 32, p. 1-21, 2019. Disponível em: https://periodicos.ufsm.br/educacaoespecial/article/view/38975/html. Acesso em: 13 mai. 2020.

\section{Correspondência}

Amanda Pereira Risso Saad - Universidade Federal de Mato Grosso do Sul, Núcleo de Hospital Universitário, Fundação Universidade Federal de Mato Grosso do Sul, Campo Grande, Mato Grosso do Sul - Brasil.

CEP: $79070-900$

\section{(i) (8)}

EY This work is licensed under a Creative Commons Attribution-NonCommercial 4.0 International (CC BY-NC 4.0) 